\title{
3D Printing as a Technology Enabler for Electrical Machines: Manufacturing and Testing of a Salient Pole Rotor for SRM
}

\author{
Leonidas Gargalis, Vincenzo Madonna, Paolo Giangrande, Mark Hardy, Ian Ashcroft, \\ Michael Galea and Richard Hague
}

\begin{abstract}
Among the various technology enablers for modern electrical machines, additive manufacturing plays a key role. The advantage of having a precise control of the shape of ferromagnetic structures, whilst achieving good electromagnetic performance, fits well with the design requirements of rotating electrical machines. To a certain extent, some of the physical properties of the material can be "tuned", allowing for quick trade-off studies (i.e., prototyping), as opposed to conventional manufacturing techniques. Despite being considered an enabling technology, 3D printing of soft magnetic materials for electric motors is still at an embryonic stage. This work, thus, aims in providing an initial proof of concept. For the purpose, a switched reluctance machine is chosen as a case study. Its rotor core is additively manufactured through selective laser melting. Its performances are compared to those of an identical commercial motor featuring a laminated rotor core, via in-depth experimental tests. Initial results show that the $3 \mathrm{D}$ printed machine can actually develop the rated power, but with an efficiency reduction.
\end{abstract}

Index Terms - 3D Printing, Electric Motors, Additive Manufacturing, Selective Laser Melting, Switched Reluctance Machine

\section{INTRODUCTION}

In the last two decades, the development and commercialization of high performance magnetic and insulating materials, together with the introduction of unconventional cooling systems, have allowed electrical machines (EMs) to achieve outstanding power density and efficiency levels [1]. The ever-increasing request for high power and low weight EMs, mainly pushed by the transportation industry, is breaking new grounds for socalled enabling technologies. From a system level point of view, the widespread development of fast-switching power electronics converters has contributed in achieving very-high speed machines, with an excellent power to weight ratio [2]. At the same time, the concept of physics of failure [3-7], when applied to EMs' insulation systems and power electronics converters, is seen as a viable methodology for

This work was partially funded by the University of Nottingham Propulsion Futures Beacon. (Corresponding Author: L. Gargalis)

L. Gargalis, I Ashcroft and Richard Hague are with the Centre for Additive Manufacturing, University of Nottingham, UK. (email: Leonidas.Gargalis@nottingham.ac.uk)

V. Madonna, P. Giangrande and M. Galea are with the Power Electronics, Machines and Control Research Group (PEMC), University of Nottingham, UK. (email: Vincenzo.madonna1@nottingham.ac.uk)

M. Galea is also with the Key Laboratory of More Electric Aircraft Technology of Zhejiang Province, Ningbo 315100, China. better exploiting the thermal and electrical capabilities of electrical insulating systems, leading to compact designs [8].

The scientific community $[9,10]$ alongside with a number of international bodies / agencies [11-13], seem to agree that future electrification roadmaps can only be achieved by relying on a number of "unconventional" technology enablers including superconductivity [14], high energy density electrochemical storage devices [15], additive manufacturing etc.. Among these, metal additive manufacturing (AM) and more specifically selective laser melting (SLM), presents undoubtedly the highest technology readiness level (TRL), when applied to EM design [16-18].

$\mathrm{AM}$ allows to precisely manufacture virtually any object with high geometrical complexity, by progressively depositing single layers of material, with the limits thus being a) the maximum build for a single part (i.e., 3D printer "size") and b) the minimum resolution. As opposed to more conventional manufacturing techniques, such as laser / plasma cutting and other machining methods, AM is considerably more sustainable, as the wasted material during manufacturing is minimum [17]. Another perceived advantage is the possibility for rapid prototyping, before mass-production. Indeed, AM does not require any stamping (i.e., pressing) die for manufacturing a new part / component.

The application of AM to EM design is still at an early stage, although various recent works have proposed $3 \mathrm{D}$ printed solutions for both magnetic $[17,18]$ and nonmagnetic EM parts [16, 19]. A suitable manufacturing method for 3D printing metallic part is the so-called SLM [20], which has also recently been used for processing soft magnetic materials. In SLM, various layers are stacked one on top of the other by melting a metallic powder through a high-intensity laser [21]. Such procedure is followed by a rapid melting / cooling process leading to a fine grain microstructure [22].

In [18], the viability of the SLM technique for 3D printing the rotor of a synchronous reluctance machine is proven. Various manufacturing details, as well as the material's magnetization curve, are provided, without, however, including experimental results on the actual machine. In [23], finite element (FE) simulations are used for quantifying the efficiency improvement arising from AM applied to a synchronous reluctance machine. In [24], a 3D printed rotor for a permanent magnet machine is developed. Its magnetic anisotropy is increased thanks to AM, leading to an improved senseless control capability.

This paper aims at providing a comprehensive, experiment-based analysis of an additively manufactured rotor for a switched reluctance machine (SRM). For doing so, a commercial machine, with laminated rotor core is 
initially selected. Its rotor is replaced with a 3D printed one, whose composition features a $5 \%$ w.t. silicon content. The material's mechanical and magnetic properties are initially characterized, before moving to the rotor manufacturing stage. Once the 3D printed rotor is manufactured and integrated in the commercial SRM stator, its electromagnetic performance is evaluated though experimental tests and apprised to the "benchmark" machine. As a main result it is found that the 3D printed SRM is able to actually develop the rated torque despite an efficiency decrement, caused by the increased losses in the solid rotor structure.

\section{COMMERCIAL SRM}

This Section gives a brief introduction on the theory and operations of SRMs. The benchmark machine is then presented, by providing its main geometrical dimensions and properties.

\section{A. Introduction to SRMs}

SRMs have been known since the nineteenth century [27], but their requirement for non-standard control, as opposed to e.g. DC or induction machines, has prevented their widespread adoption/use. With the availability of modern power electronics converters, there is renewed interest in SRMs and they are being proposed for various applications, including automotive [28] and aerospace [29].

SRMs are characterized by salient poles on both the stator and rotor. When a stator phase is excited, torque is produced by the tendency of the rotor aligning to the minimum reluctance position. Therefore, the stator phases are switched "on and off" according to the rotor position, so that a continuous motion is obtained [30]. For doing so, a suitable power electronics converter and control algorithm are necessary. For a 3-phase SRM, the basic converter topology counts 6 switches and as many freewheeling diodes, although their configuration differs from that for conventional AC machines. The main advantages of SRMs are the absence of permanent magnets and the ruggedness and robust structure [31]. Thus, they are particularly suited for harsh operating environments.

\section{B. The benchmark machine}

The benchmark motor is a commercial $\approx 1.1 \mathrm{~kW}$ rated power, three-phase SRM with a 12/8 configuration (i.e., 12 stator teeth and 8 rotor teeth). Its main geometrical dimensions and parameters are listed in Table I.

TABLE I

PARAMETERS OF THE BENCHMARK SRM

\begin{tabular}{ll}
\hline \hline & Value \\
\hline Rated Speed & $600 \mathrm{rpm}$ \\
Rated Torque & $17.2 \mathrm{Nm}$ \\
DC Link Voltage & $360 \mathrm{~V}$ \\
Stator Poles & 12 \\
Rotor Poles & 8 \\
Axial Length & $104 \mathrm{~mm}$ \\
Stator Outer Diameter & $150 \mathrm{~mm}$ \\
Airgap & $0.5 \mathrm{~mm}$ \\
Number of Turns per coil & 220 \\
Control strategy & Soft switching \\
\hline \hline
\end{tabular}

The cross-sectional view of the machine and its winding layout are shown in Fig. 1. Each phase has a total of 4 coils, and each coils features 220 turns. A standard, commercial converter implementing a soft-switching strategy is used for controlling the machine. The controller receives the rotor position feedback from a simple optical position sensor based on three photodiodes and three light emitting devices. Based on the rotor position, the control algorithm generates and sends the control signals to the switching devices. A digital hysteresis control algorithm is used for maintaining a flat-topped current when the SRM operates at low speed (i.e., the phases voltage is chopped for maintaining the current within the hysteresis band). The turn-on and turn-off angles of each phase are automatically selected, according to the instantaneous torque request, for minimizing the required current (i.e., maximum torque per ampere algorithm).

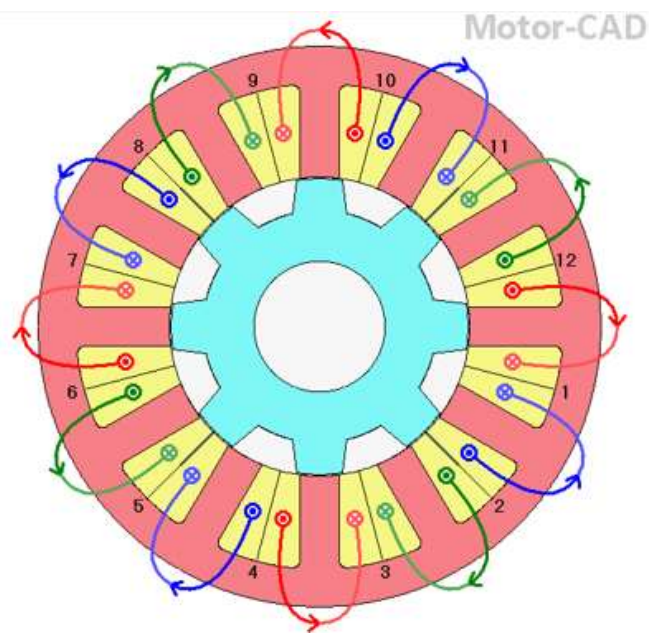

Fig. 1. Cross-sectional view and winding layout of the case-study PMSM

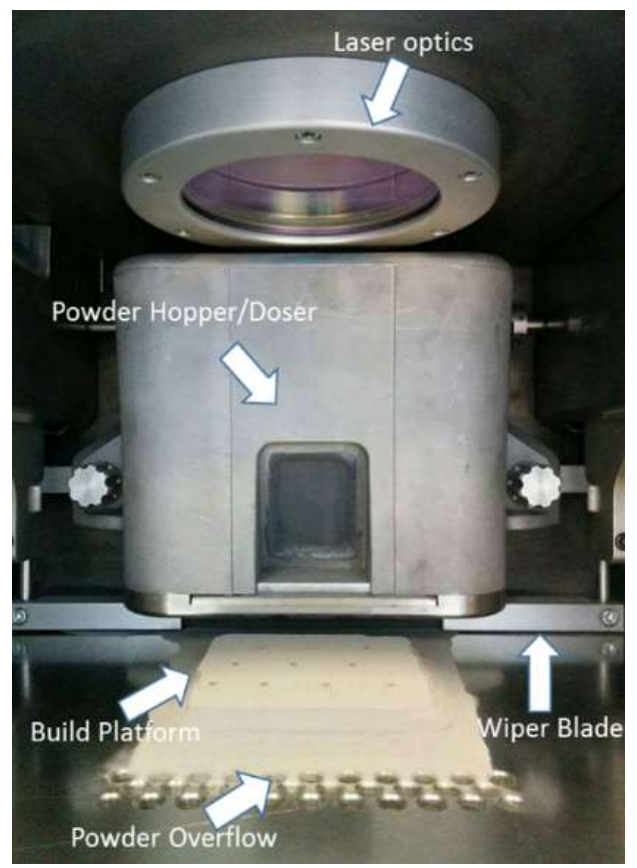

Fig. 2. Build chamber configuration.

\section{MATERIAl DeVEloPMENT AND Rotor PRINTING}

Silicon-based steels (i.e. Fe-Si) are conventionally adopted for manufacturing standard soft magnetic materials for EM laminations [32]. The higher silicon content helps in reducing the electrical conductivity of the alloy, and thus acts in directly reducing eddy-current losses. Commercial machines, including the case study SRM, adopt silicon content of approximately $3 \%$ w.t., while in high performance 
aerospace motors cores, up-to c.a. $6 \%$ silicon content in weight can be found.

In this study a silicon steel powder with a 5\% silicon content (Fe-5.0\%w.t. $\mathrm{Si}$ ) is produced, by mixing a pre-alloyed high silicon steel powder with high purity Fe powder. The powder blend results in an average particle diameter of $36.2 \mu \mathrm{m}$.

The SLM process employs a Renishaw AM125 SLM machine equipped with a $200 \mathrm{~W}$ D-Series redPOWER ytterbium fibre continuous wavelength laser. Carrying out the process in an argon atmosphere minimizes oxidation. The configuration of the build chamber is shown in Fig. 2. Samples with different shapes are produced for determining physical, magnetic and mechanical properties of the developed material. In particular, cylindrical samples are used for determining the magnetic performance of the material with the use of a vibrating sample magnetometer (VSM), whilst dog-bones are employed for performing tensile tests. The resulting magnetization curve is reported in Fig. 3 where the magnetic moment per unit volume $M$ is plotted against the magnetic field magnitude.

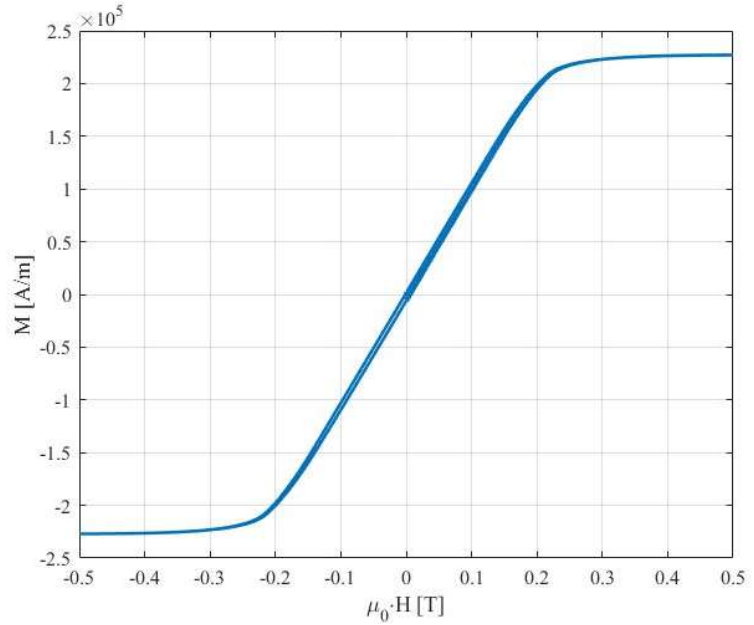

Fig. 3. Magnetization curve of additively manufactured Fe-5\%w.t. Si samples.

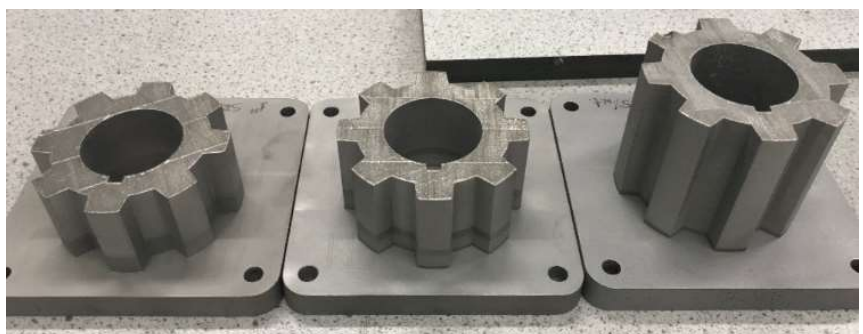

Fig. 4. Three additively manufactured SRM rotor blocks.

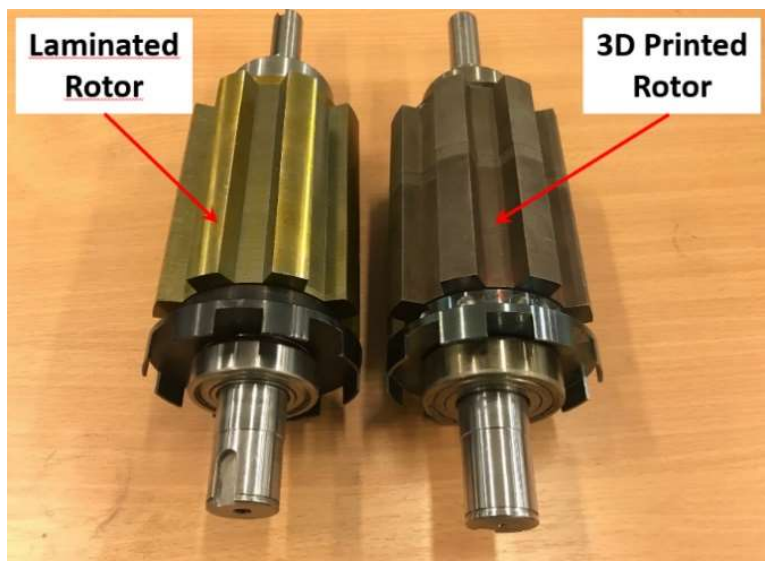

Fig. 5. Conventional and additively manufactured SRM rotor core.
After having tuned and optimized the processing parameters of the AM process, the SRM rotor is printed. Its geometry is identical to that of the benchmark EM, although its construction is solid. Due to build height restrictions in the SLM machine, the AM motor is axially divided in three blocks that are shown in Fig. 4. Clearly, the larger the number of axial segments, the lower the eddy current losses in the magnetic structure, since each segment is electrically insulated through a non-conductive coating.

The SRM shaft has been manufactured via conventional machining techniques and the three rotor blocks have been assembled on it as shown in Fig. 5. Finally, high precision bearings have also been fitted on the shaft.

\section{FE ANALYSIS}

A 2D FE analysis has been carried out for the benchmark machine. Such a preliminary analysis serves the purpose of a) determining the iron loss distribution and b) checking if there is any rotational speed characterized by excessive torque ripple. Point a) is necessary for establishing the rotor's share of iron losses, so that the results from the experimental tests can be better analyzed. In other words, the knowledge of the rotor loss magnitude for the benchmark machine alongside with the measured total losses for the 3D printed machine, allows to quantify the rotor loss variation (i.e., laminated/benchmark vs 3D printed) according to (1), where $P_{r o t}$ are the rotor losses, $P_{e l}$ is the electrical input power, $P_{\text {Joule }}$ are the winding Joule losses, $P_{\text {stat }}$ are the stator iron losses, $T$ is the shaft torque and $\omega_{m}$ is the mechanical speed.

$$
P_{\text {rot }} \approx P_{\text {el }}-P_{\text {Joule }}-P_{\text {stat }}-T \cdot \omega_{m}
$$

Since the EM operates at relatively low speed, windage losses are neglected.

Point b), on the other hand, needs to be verified mainly for practical and safety purposes. Indeed, excessive torque ripple might damage mechanical couplings, and thus should be avoided.

Fig. 6 shows the flux map and magnetic field lines of the laminated machine operating at base speed and delivering the rated (average) torque of $18.7 \mathrm{Nm}$, whilst Fig. 7 reports the iron loss distribution (per unit mass), under the same operating condition.

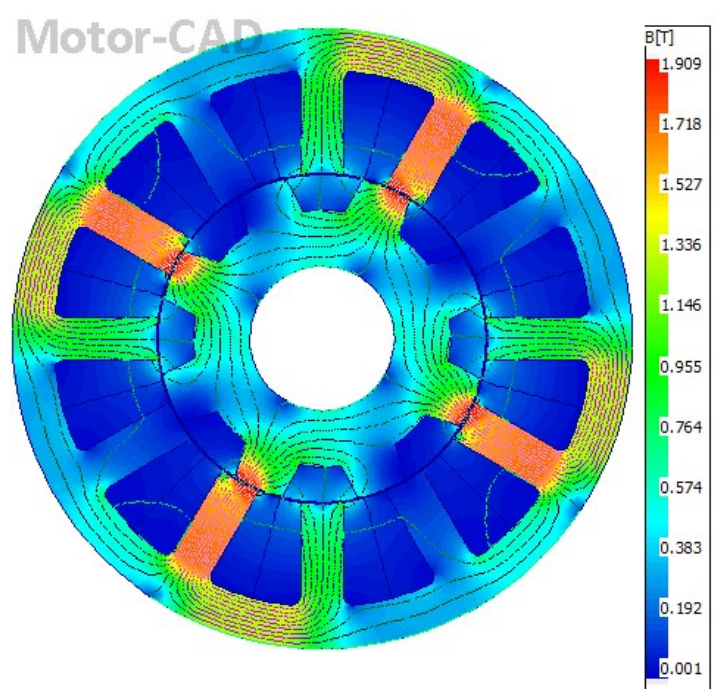

Fig. 6. Flux density map and magnetic field lines for the benchmark/laminated SRM operating at rated condition. 
Despite the visible loss concentration in the rotor teeth tips, the rotor losses share over the total iron losses is less than $20 \%$, as reported in Table II, where the loss results obtained from the FE simulation are summarized. These include also the Joule losses, which are one order of magnitude higher than iron losses.

TABLE II

LOSS DISTRIBUTION FOR THE BENCHMARK SRM (RATED CONDITION)

\begin{tabular}{cc} 
Loss component & Magnitude \\
\hline Stator iron & $11.3 \mathrm{~W}$ \\
Rotor (total) & $2.7 \mathrm{~W}$ \\
Joule losses & $615 \mathrm{~W}$ \\
\hline \hline
\end{tabular}

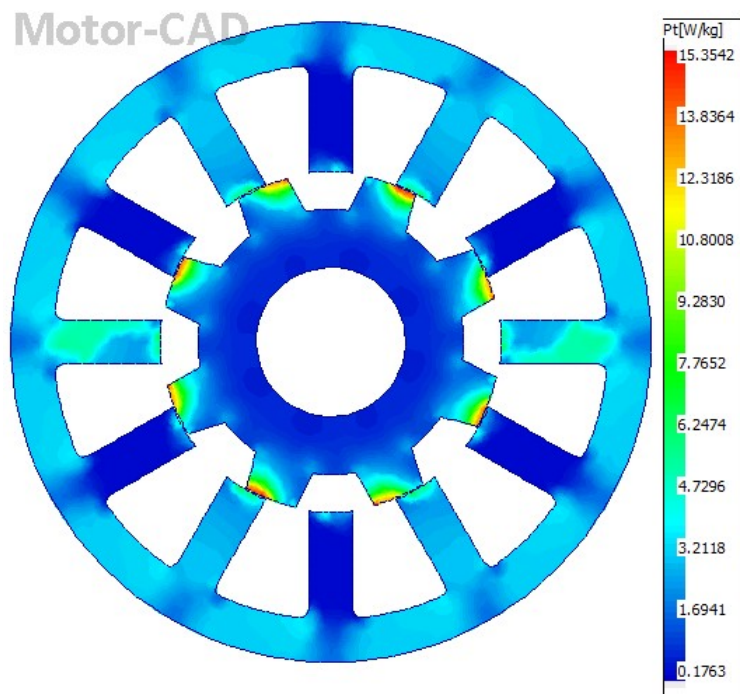

Fig. 7. Iron loss distribution for the benchmark SRM operating at rated condition.

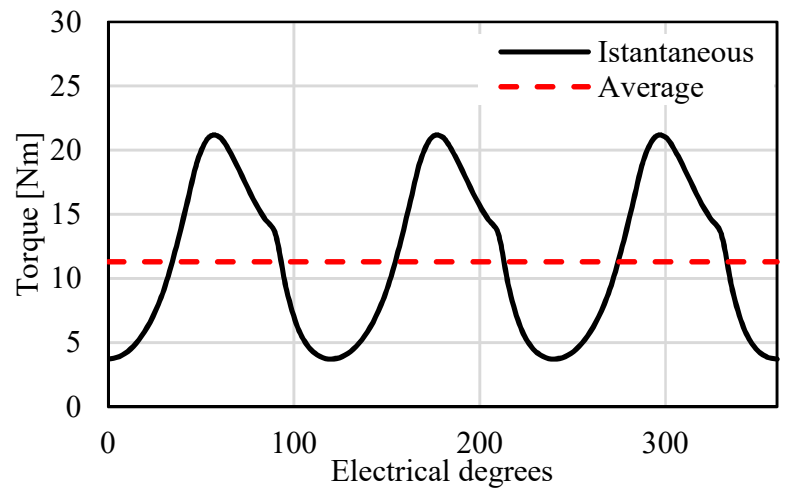

Fig. 8. Shaft torque for the benchmark SRM operating at $1000 \mathrm{rpm}$ obtained through $\mathrm{FE}$ analysis.

A speed-sweep analysis has been carried out for determining if there is any particular operating speed range in which the SRM develops excessive torque ripple. As a result it has been found that within the range $800-1200 \mathrm{rpm}$ an anomalous ripple is detected. This is visible in Fig. 8, where the instantaneous torque developed at $1000 \mathrm{rpm}$ is plotted. Its torque ripple is higher than $120 \%$. Therefore, experimental tests with the machine operating within the aforementioned speed range should be avoided.

\section{EXPERIMENTAL TESTS}

This Section describes the experimental test procedure and reports the main results for both the benchmark and the 3D printed SRMs.

\section{A. Test-bed description}

In order to test the electromechanical performances of the manufactured 3D printed SRM and to compare them with the benchmark machine, the test-bed shown in Fig. 9 has been used. The description of each component / instrument is reported in Table III.

The SRM is flange-mounted to an "L" plate. Its shaft is mechanically coupled through a Magtrol ${ }^{\mathbb{R}}$ torquemeter to a $70 \mathrm{~kW}$, variable-speed Oswald ${ }^{\circledR}$ induction motor. The load induction machine is torque controlled via an Emerson Unidrive $^{\circledR}$ three-phase inverter.

Phase current and voltage are measured through a halleffect current clamp and a differential probe respectively. These are connected to a Lecroy ${ }^{\circledR}$ Wavetouch oscilloscope for instantaneous time-domain analysis and logging. In addition, the instantaneous electric power analysis is carried out using a Rode \& Shwarz power analyser, which records and processes the phase current and voltage.

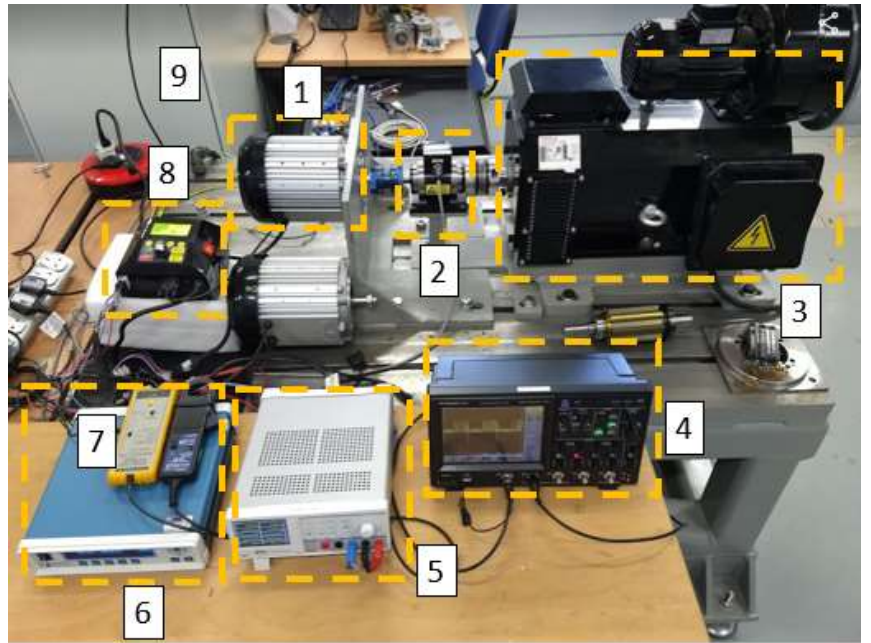

Fig. 9. Experimental test-bed (the description is provided in Table III).

TABLE III

TEST-BED COMPONENTS / INSTRUMENTS

\begin{tabular}{cl}
\hline \hline $\begin{array}{c}\text { ID } \\
\text { See Fig. } 9\end{array}$ & \multicolumn{1}{c}{ Description } \\
\hline 1 & 3D printed SRM \\
2 & Magtrol torquemeter \\
3 & Oswald induction machine (load) \\
4 & Lecroy Wavetouch ${ }^{\circledR}$ oscilloscope \\
5 & Rode \& Shwarz power analyzer \\
6 & Magtrol torque / speed datalogger \\
7 & Pico current and voltage probes \\
8 & Benchmark/Laminated SRM drive (converter) \\
9 & Induction machine drive cabinet \\
\hline \hline
\end{tabular}

\section{B. Tests results}

Both machines (i.e., benchmark SRM and 3D printed one) have been tested at base speed delivering the maximum torque and at 2.5 times rated speed. At the rated speed (i.e., $600 \mathrm{rpm})$, the SRM fitted with the 3D printed rotor produces $13 \%$ less torque compared to the benchmark SRM, as can be seen in Table IV, where the measured electrical and mechanical quantities at rated speed are tabulated. When the operating speed is increased up to $1500 \mathrm{rpm}$, the 3D SRM's performance improves both in terms of maximum mechanical power as well as in terms of efficiency, as can be observed in Table $\mathrm{V}$, where the electric and mechanical power quantities measured at $1500 \mathrm{rpm}$ and maximum torque are listed. The next sub-section will provide a more detailed discussion on the obtained results. 
TABLE IV

MEAsured Quantities at BASE SpeEd

\begin{tabular}{c|cc}
\hline \hline $\begin{array}{c}\text { Measured } \\
\text { quantities }\end{array}$ & $\begin{array}{c}\text { Benchmark } \\
\text { SRM }\end{array}$ & $\begin{array}{c}\text { 3D Printed } \\
\text { Rotor }\end{array}$ \\
\hline Mechanical Power & $1170 \mathrm{~W}$ & $1020 \mathrm{~W}$ \\
Electric Power & $1995 \mathrm{~W}$ & $2130 \mathrm{~W}$ \\
Average phase current & $3.27 \mathrm{~A}$ & $3.31 \mathrm{~W}$ \\
RMS phase current & $4.11 \mathrm{~A}$ & $4.17 \mathrm{~A}$ \\
\hline \hline
\end{tabular}

TABLE V

MeAsuRed Quantities AT 2.5 TIMES the BASE SPEED

\begin{tabular}{c|cc}
\hline \hline $\begin{array}{c}\text { Measured } \\
\text { quantities }\end{array}$ & $\begin{array}{c}\text { Benchmark } \\
\text { SRM }\end{array}$ & $\begin{array}{c}\text { 3D Printed } \\
\text { Rotor }\end{array}$ \\
\hline Mechanical Power & $960 \mathrm{~W}$ & $925 \mathrm{~W}$ \\
Electric Power & $1149 \mathrm{~W}$ & $1420 \mathrm{~W}$ \\
Average phase current & $1.74 \mathrm{~A}$ & $1.77 \mathrm{~W}$ \\
RMS phase current & $2.13 \mathrm{~A}$ & $2.44 \mathrm{~A}$ \\
\hline \hline
\end{tabular}

\section{Discussion on the obtained results}

In order to provide a more insightful discussion on the experimental results, it is worthy reporting the measured electric quantities in the time domain for both SRMs, as done in Figs. 10 to 13. In particular, in Figs. 10 and 11 the instantaneous electric quantities for the benchmark SRM running at base speed are plotted. Similarly, Figs. 12 and 13 report the measured electric quantities for the SRM with the $3 \mathrm{D}$ printed rotor operating at $600 \mathrm{rpm}$.
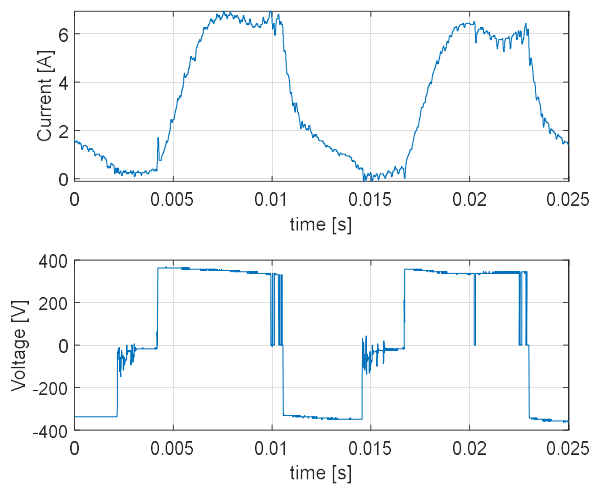

Fig. 10. Voltage and current for the benchmark SRM at base speed and rated torque.

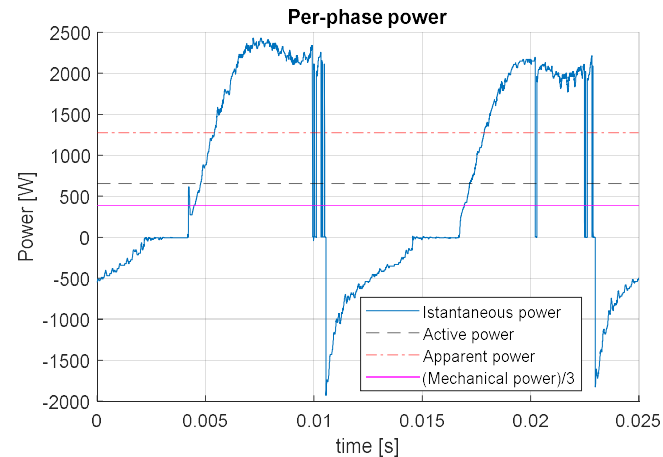

Fig. 11. Instantaneous power for the benchmark SRM at base speed and rated torque.

A comment can be made on the voltage waveforms for both machines. For the benchmark EM (i.e., Fig. 10), it is possible to observe the soft-chopping action, necessary to maintain the current within the hysteresis band. On the contrary, a flat-topped voltage waveform is recorded for the 3D printed rotor SRM (i.e., Fig. 12). This indicates that the power electronics converter has actually reached its current limit. Such an observation is also confirmed by the timeperiod of current / voltage waveforms. Indeed, for the benchmark EM, two electrical periods last $25 \mathrm{~ms}$, whilst they last c.a. $27 \mathrm{~ms}$ for the $3 \mathrm{D}$ printed rotor SRM. Accordingly, by calculating the mechanical speed as in (2), where $f_{e l}$ is the electrical frequency, it is possible to verify that the 3D SRM is actually slowing down by c.a. $45 \mathrm{rpm}$.

$$
\omega_{m}[\mathrm{rpm}]=\frac{60 \cdot f_{e l}}{\text { Rotor Poles }}
$$

Further considerations can be made relying on the instantaneous power waveforms (Figs. 11 and 13), as well as the average power values reported in Tables IV and V. First of all, by calculating the ratio between active and apparent power, it is possible to obtain the power factor. At base speed, the latter, is equal to 0.52 for both machines. This interesting result indicates that, in principle, the volt-ampere rating of the power converter for a $3 \mathrm{D}$ printed rotor SRM can be identical to a standard laminated one (with the same rated power).
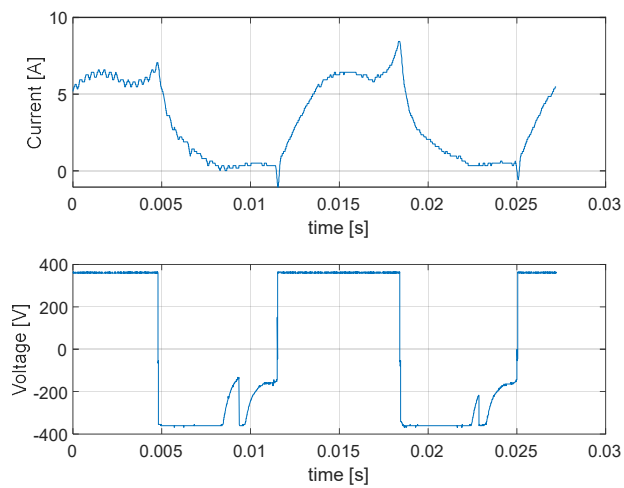

Fig. 12. Voltage and current for the 3D printed SRM at base speed and rated torque.

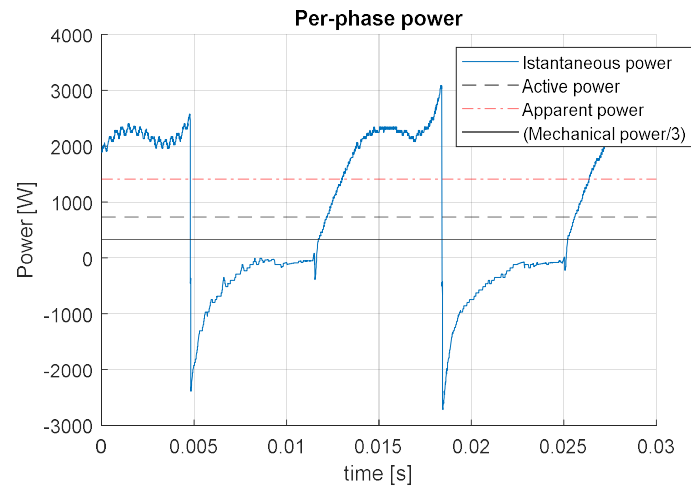

Fig. 13. Instantaneous power for the 3D printed SRM at base speed and rated torque.

However, for the SRM at hand, because of the increased rotor losses caused by the solid rotor structure, the power converter results slightly underrated. In fact, the RMS input power for the benchmark SRM is $3.83 \mathrm{kVA}$, whilst it is equal to $4.24 \mathrm{kVA}$ for the $3 \mathrm{D}$ printed rotor SRM. The larger demanded apparent power is needed for partially compensating the efficiency reduction, which can be calculated as the ratio between average mechanical power and average electric power. In particular, the efficiency reduction (at base speed) is c.a. $22 \%$.

As the operating speed is increased to 1500 , the efficiency rises to $83 \%$ for the benchmark SRM and $65 \%$ for the 3D printed one. Such a conclusion could be also reached by calculating the rotor loss share for the $3 \mathrm{D}$ printed machine as in (1). This is quite high when the machine operates at 600 $\mathrm{rpm}$, as it peaks at c.a. $500 \mathrm{~W}$, whilst is negligible for the benchmark machine. It keep being quite elevated, even when the machine operates at higher speed, although, in this case, the overall efficiency increases because of the Joule loss 
reduction (i.e., the RMS phase current decreases as the speed increases for constant / decreasing power operations).

\section{CONCLUSIONS}

Additive manufacturing is considered one of the technology enablers for achieving near-future power density targets in electric drives. Although there is a wide ongoing research on the topic, few are the examples of operational $3 \mathrm{D}$ printed active parts for electrical machines. The main objective of this work is to prove the concept that additive manufacturing for electric motors is actually viable and feasible from a manufacturing and technological point of view. Therefore, the focus of the paper is mainly in

\section{REFERENCES}

[1] Giangrande, P., Hill, C.I., Bozhko, S.V., Gerada, C., "A Novel MultiLevel Electro-Mechanical Actuator Virtual Testing and Analysis Tool", $7^{\text {th }}$ IET International Conference on Power Electronics, Machines and Drives (PEMD), p.p.0249, 2014

[2] V. Madonna, G. Migliazza, P. Giangrande, E. Lorenzani, G. Buticchi, and M. Galea, "The Rebirth of the Current Source Inverter: Advantages for Aerospace Motor Design," IEEE Industrial Electronics Magazine, vol. 13, no. 4, pp. 65-76, 2019.

[3] H. Wang et al., "Transitioning to Physics-of-Failure as a Reliability Driver in Power Electronics," IEEE Journal of Emerging and Selected Topics in Power Electronics, vol. 2, no. 1, pp. 97-114, 2014.

[4] V. Madonna, P. Giangrande, and M. Galea, "Introducing Physics of Failure Considerations in the Electrical Machines Design," presented at the IEMDC 2019 - International Electric Machines \& Drives Conference, 2019.

[5] H. Wang, M. Liserre, and F. Blaabjerg, "Toward Reliable Power Electronics: Challenges, Design Tools, and Opportunities," IEEE Industrial Electronics Magazine, vol. 7, no. 2, pp. 17-26, 2013.

[6] P. Giangrande, V. Madonna, S. Nuzzo, and M. Galea, "Moving Towards a Reliability-Oriented Design Approach of Low-Voltage Electrical Machines by Including Insulation Thermal Aging Considerations," IEEE Transactions on Transportation Electrification, pp. 1-1, 2020 .

[7] M. Galea, P. Giangrande, V. Madonna, and G. Buticchi, "Insulation systems for electrical machines: Reliability MUST become a main design objective," IEEE Industrial Electronics Magazine, vol. 14, no. $1,2020$.

[8] Al-Timimy A., Giangrande P., Degano M.,Xu Z., Galea M., Gerada, C., Lo Calzo G., Zhang H., Xia L., "Design and Losses Analysis of a High Power Density Machine for Flooded Pump Applications", XXI Int. Conf. Electrical Machines (ICEM), pp. 1480-1486, 2016.

[9] B. Sarlioglu and C. T. Morris, "More Electric Aircraft: Review, Challenges, and Opportunities for Commercial Transport Aircraft," IEEE Transactions on Transportation Electrification, vol. 1, no. 1, pp 54-64, 2015.

[10] V. Madonna, P. Giangrande, and M. Galea, "Electrical Power Generation in Aircraft: Review, Challenges, and Opportunities," IEEE Transactions on Transportation Electrification, vol. 4, no. 3, pp. 646659, 2018.

[11] R. H. Jansen, C. Bowman, A. Jankovsky, R. Dyson, and J. Felder, "Overview of NASA Electrified Aircraft Propulsion Research for Large Subsonic Transports," AIAA Propulsion and Energy 2017 Forum; 10-12 Jul. 2017; Atlanta, GA; United States. Available: https://ntrs.nasa.gov/search.jsp? $R=20170006235$ Accessed: Dec. 2017

[12] NASA, "Visions of the Future: Hybrid Electric Aircraft Propulsion," AIAA Aircraft Electric/Hybrid-Electric Power \& Propulsion Workshop, July 28, 2016.2 Available: https://ntrs.nasa.gov/archive/nasa/casi.ntrs.nasa.gov/20170002633.pdf Accessed: Dec. 2017.

[13] "Insight_07 - Electrical Power Systems," UK Aerospace Technology Institute; July 2018.

[14] C. A. Luongo et al., "Next Generation More-Electric Aircraft: A Potential Application for HTS Superconductors," IEEE Transactions on Applied Superconductivity, vol. 19, no. 3, pp. 1055-1068, 2009.

[15] A. Damiano et al., "Batteries for Aerospace: a Brief Review," in 2018 AEIT International Annual Conference, 2018, pp. 1-6.

[16] R. Wrobel and B. Mecrow, "Additive Manufacturing in Construction of Electrical Machines - A Review," in 2019 IEEE Workshop on demonstrating how from the raw materials (i.e., metallic powder), it is possible to use AM/SLM in order to manufacture and spin an actual rotor for an electrical machine. Clearly, because the rotor is a relatively simple solid block, its losses are considerably higher with respect to a standard laminated machine. However, thanks to the strengths of additive manufacturing, a more lightweight complex geometrical rotor can be built for optimizing the overall machine's efficiency. Thus, future work will investigate through a finite element optimization, how the magnetic structure can be modified in order to mitigate the effect of eddy current losses.

Electrical Machines Design, Control and Diagnosis (WEMDCD), 2019 , vol. 1, pp. 15-22.

[17] M. Garibaldi, C. Gerada, I. Ashcroft, R. Hague, and H. Morvan, "The impact of additive manufacturing on the development of electrical machines for MEA Applications: A feasibility study," in MEA2015 More Electric Aircraft, 2015.

[18] R. Wrobel and A. Hussein, "Design Considerations of Heat Guides Fabricated Using Additive Manufacturing for Enhanced Heat Transfer in Electrical Machines," in 2018 IEEE Energy Conversion Congress and Exposition (ECCE), 2018, pp. 6506-6513.

[19] E. Aguilera et al., "3D printing of electro mechanical systems," in Proceedings of the Solid Freeform Fabrication Symposium, 2013, pp. 950-961.

[20] Z.-Y. Zhang, K. J. Jhong, C.-W. Cheng, P.-W. Huang, M.-C. Tsai, and W.-H. Lee, "Metal 3D printing of synchronous reluctance motor," in 2016 IEEE International Conference on Industrial Technology (ICIT), 2016, pp. 1125-1128: IEEE.

[21] C. Silbernagel, L. Gargalis, I. Ashcroft, R. Hague, M. Galea, and P. Dickens, "Electrical resistivity of pure copper processed by mediumpowered laser powder bed fusion additive manufacturing for use in electromagnetic applications," Additive Manufacturing, vol. 29, p. 100831, 2019/10/01/2019.

[22] H. Tiismus, A. Kallaste, A. Belahcen, A. Rassõlkin, and T. Vaimann, "Challenges of Additive Manufacturing of Electrical Machines," in 2019 IEEE 12th International Symposium on Diagnostics for Electrical Machines, Power Electronics and Drives (SDEMPED), 2019, pp. 44-48: IEEE.

[23] N. Hopkinson, R. Hague, and P. Dickens, Rapid manufacturing: an industrial revolution for the digital age. John Wiley \& Sons, 2006.

[24] M. Garibaldi, I. Ashcroft, M. Simonelli, and R. Hague, "Metallurgy of high-silicon steel parts produced using Selective Laser Melting," Acta Materialia, vol. 110, no. Supplement C, pp. 207-216, 2016/05/15/ 2016.

[25] H. Hong, H. Liu, G. Jeong, and J. Lee, "Design of high-end SynRM based on 3D printing technology," in 2016 IEEE Conference on Electromagnetic Field Computation (CEFC), 2016, pp. 1-1.

[26] S. Lammers et al., "Additive Manufacturing of a lightweight rotor for a permanent magnet synchronous machine," in 2016 6th International Electric Drives Production Conference (EDPC), 2016, pp. 41-45.

[27] K. Vijayakumar, R. Karthikeyan, S. Paramasivam, R. Arumugam, and K. N. Srinivas, "Switched Reluctance Motor Modeling, Design, Simulation, and Analysis: A Comprehensive Review," IEEE Transactions on Magnetics, vol. 44, no. 12, pp. 4605-4617, 2008.

[28] M. Krishnamurthy, C. S. Edrington, A. Emadi, P. Asadi, M. Ehsani, and B. Fahimi, "Making the case for applications of switched reluctance motor technology in automotive products," IEEE Transactions on Power Electronics, vol. 21, no. 3, pp. 659-675, 2006.

[29] M. E. Elbuluk and M. D. Kankam, "Potential starter/generator technologies for future aerospace applications," IEEE Aerospace and Electronic Systems Magazine, vol. 12, no. 5, pp. 24-31, 1997.

[30] T. J. E. Miller, "Optimal design of switched reluctance motors," IEEE Transactions on Industrial Electronics, vol. 49, no. 1, pp. 15-27, 2002.

[31] Al-Timimy A.,Giangrande P., Degano M., Galea M., Gerada, C., " Comparative study of permanent magnet-synchronous and permanent magnet-flux switching machines for high torque to inertia applications", Proceedings-2017 IEEE Workshop on Electrical Machines Design, Control and Diagnosis (WEMDCD), pp.45-51, UK, 2017

[32] Odhano S.A., Giangrande P., Bojoi R., Gerada C., "Self-commisioning of Interior Permanent Magnet Synchronous Motor Drives With HighFrequency Current Injection", Energy Conversion Congress and Exposition, pp. 3852-3859, 2013. 


\section{BIOGRAPHIES}

Leonidas Gargalis is a Research Assistant at the Centre for Additive Manufacturing (CfAM) working towards the completion of his $\mathrm{PhD}$. After he received a Marie Curie Doctoral Fellowship in 2016, he joined CfAM and the Institute for Aerospace Technology at the University of Nottingham. His research has focused on developing soft magnetic alloys using selective laser melting for the design and fabrication of rotating electrical machines. His research interests in metal AM span between process optimisation, such as parametric studies for materials qualification, and characterisation of $3 \mathrm{D}$ printed materials such as the microstructural, mechanical and electromagnetic properties.

Vincenzo Madonna received the MSc degree in Electrical Engineering from the University of Bologna, Italy, in 2016 and the PhD degree in Electrical Machines Design from the University of Nottingham, UK in 2020. In 2016 he was awarded a prestigious Marie Curie Doctora Fellowship and joined the Institute for Aerospace Technology in Nottingham. He is currently a Research Fellow with the Propulsion Futures Beacon of Excellence at the University of Nottingham. His research interests include design, thermal management and lifetime prediction modelling of electrical machines.

Paolo Giangrande received his $\mathrm{PhD}$ in electrical engineering at the Politecnico of Bari in 2011. From 2012 until 2019, he has been a Research Fellow at the University of Nottingham (UK), within the Power Electronics, Machines and Control (PEMC) group. In 2019 he was appointed Senior Research Fellow within the same group, where he is also the Head of the Accelerated Lifetime Testing Laboratory. His main research interests include design and testing of electromechanical actuators for aerospace, thermal management of high-performance electric drives and reliability of electrical machines.

Mark Hardy is Senior Research Technician at the Centre for Additive Manufacture, University of Nottingham (UK). He has been working in the
AM field for the past 10 years and has a background of over 20 year's Mechanical Engineering experience in the Power Generation sector. His main focus is on Selective Laser Melting with interests in all aspects of Additive Manufacturing.

Ian Ashcroft is Professor of Solid Mechanics, member of the Centre for Additive Manufacturing (CfAM) and Head of Department-Mechanical, Materials and Manufacturing, Faculty of Engineering, University of Nottingham. His areas of knowledge encompass static and dynamic loading, design optimisation, heat and mass transport and material microstructure understanding. His current research interests include materials testing and characterization, multi-physics finite element analysis, design for manufacture and structural and multi-objective optimization.

Michael Galea received his $\mathrm{PhD}$ in electrical machines design from the University of Nottingham, where he has also worked as a Research Fellow. $\mathrm{He}$ is currently the Head of the School of Aerospace in the University of Nottingham, Ningbo, China and a Professor in Electrical Machines and Drives. His main research interests are design, analysis and thermal management of electrical machines and drives, the more electric aircraft and electrified and hybrid propulsion.

Richard Hague is Professor of Innovative Manufacturing in the Department of Mechanical, Materials and Manufacturing Engineering at the University of Nottingham, Head of the Centre for Additive Manufacturing (CfAM) and Director of the EPSRC Centre for Innovative Manufacturing in Additive Manufacturing. He has been working in the AM field for 20 years and has a background of leading and managing large multi-disciplinary, multi-partner research projects. Prof Hague's research interests are focused on AM specific processes, materials and design / design systems across a wide spectrum of industrial sectors with a particular interest in design / design systems. 